\title{
Imprensa feminista no contexto das lutas das mulheres: Ativismo midiático, cidadania e novas formas de resistência ${ }^{1}$
}

\author{
Karina Janz WOITOWICZ ${ }^{2}$
}

\begin{abstract}
RESUMO
Entender a mídia alternativa produzida pelo movimento feminista como um espaço de construção de discursos contra-hegemônicos e de identidades de resistência. Essa é a proposta do presente artigo, que parte de uma reflexão sobre os usos e as apropriações da comunicação no feminismo para demarcar alguns limites e contribuições da mídia nas disputas políticas travadas pelo movimento a partir dos anos 1990. Tendo como objeto quatro publicações periódicas editadas por organizações feministas no Brasil - os jornais Fêmea, do Centro Feminista de Estudos e Assessoria; Fazendo Gênero, do grupo Transas do Corpo; Jornal da Rede, da Rede Feminista de Saúde, Direitos Sexuais e Direitos Reprodutivos; e Folha Feminista, da Sempreviva Organização Feminista -, busca-se observar as orientações editoriais que marcam o discurso da mídia alternativa, bem como identificar temas, fontes, formatos e características presentes na imprensa feminista. No trabalho, são enfocadas as lutas que pautam a mídia feminista e as estratégias de comunicação que integram as ações do movimento, projetando identidades políticas e tematizando a cidadania feminina.
\end{abstract}

Palavras-chave: imprensa alternativa; movimento feminista; contra-hegemonia; ativismo midiático.

\section{Considerações iniciais}

Ao longo do presente artigo, serão mencionadas as experiências de imprensa alternativa que marcaram algumas das principais organizações feministas brasileiras no período pós-1990 (Centro Feminista de Estudos e Assessoria - CFEMEA, Grupo Transas do Corpo, Rede Feminista de Saúde, Direitos Sexuais e Direitos Reprodutivos e Sempreviva Organização Feminista $-\mathrm{SOF})^{3}$, identificando aspectos temáticos e editoriais das publicações. Porém, para compreender o lugar ocupado por esses veículos para tematizar as lutas das mulheres, torna-se necessário recuperar historicamente o

\footnotetext{
1 Trabalho apresentado à terceira edição da Revista Ação Midiática - Estudos em Comunicação, Sociedade e Cultura, publicação ligada ao Programa de Pós-Graduação em Comunicação e Sociedade, da Universidade Federal do Paraná.

${ }^{2}$ Universidade Estadual de Ponta Grossa. Email karinajw@ hotmail.com.

${ }^{3}$ Entre as diversas organizações feministas existentes no Brasil, foram consideradas aquelas que, além de possuírem trajetória pioneira nas lutas das mulheres ainda antes dos anos 1990, desenvolvem ações ligadas à mídia impressa.
} 
contexto vivenciado pelas organizações na trajetória do feminismo no Brasil (momento de consolidação das lutas do movimento em políticas públicas, a partir dos anos 1990), bem como a presença da mídia como espaço estratégico para dar visibilidade às demandas das mulheres e tematizar sua condição de cidadania. ${ }^{4}$

Entende-se que, diante da ação sistemática do movimento feminista no atendimento às demandas das mulheres desde os anos 1960, em uma fase posterior (anos 1980-90) surgem diversos grupos temáticos, como os que tratavam da violência contra a mulher e da saúde da mulher, além do desenvolvimento do feminismo acadêmico. Nesse período de redemocratização do país, o movimento feminista assume outras características, transformando suas formas de militância por meio da profissionalização decorrente da institucionalização do movimento em organizações não governamentais e da fragmentação de temas e lutas relacionadas aos direitos das mulheres. Vale destacar, conforme observa Céli Pinto, que muitas ONGs tiveram sua origem nos movimentos sociais, sendo formadas por mulheres que já militavam no movimento e buscaram associar suas profissões ao comprometimento com as causas feministas. Porém, esse processo também foi marcado por tensões e questionamentos. ${ }^{5}$

Com o processo de redemocratização mais avançado surgia uma nova divisão entre as feministas: de um lado ficaram as que lutavam pela institucionalização do movimento e por uma aproximação da esfera estatal e, de outro, as autonomistas, que viam nessa aproximação um sinal de cooptação. (PINTO, 2003, p. 68)

Pode-se dizer, diante dessas mudanças que acompanharam o movimento

\footnotetext{
4 A noção de cidadania remete historicamente à condição de participação da vida em sociedade. $O$ conceito se desdobra em cidadania civil, voltada à garantia dos direitos individuais, em uma concepção liberal; cidadania política, marcada pela participação nas formas de organização do poder; e cidadania social, sustentada em direitos e deveres a partir de uma participação igualitária. É principalmente na dimensão da cidadania social que se inserem as práticas dos movimentos sociais.

${ }^{5}$ As feministas preocupavam-se, neste momento, com a perda da autonomia do movimento e com o seu enfraquecimento, diante da segmentação proporcionada pelas ONGs. De acordo com Céli Pinto, as ONGs "se constituem como organizações privadas sem fins lucrativos, e agem por meio de projetos destinados a populações específicas ou à defesa de causas específicas. Essas organizações são financiadas primordialmente por fundações internacionais, mas em alguns casos recebem dinheiro do próprio governo, numa espécie de terceirização e serviços e responsabilidades. Esse modelo de funcionamento, ainda que provado ser muito econômico, traz uma séria limitação: muitas vezes as ações das ONGs são pautadas pela agenda das fundações internacionais em função dos critérios estabelecidos para a dotação de fundos. Outra questão presente nesse tipo de organização é a institucionalização. Mesmo quando uma ONG surge a partir de militantes de um movimento social organizado, os compromissos que ela assume para sua própria sobrevivência transformam completamente o caráter da sua militância. A feminista não deixa de ser feminista no momento em que cria ou se associa a uma ONG, mas passa a falar de um lugar institucional que a diferencia de outras feministas que estão em outras instituições” (2003, p. 96).
} 
feminista no Brasil, que a transição da militância no movimento social para a atuação nas ONGs representou a busca por formas alternativas de intervenção, nas quais as organizações figuram como interlocutoras de interesses dos grupos que representam, atendendo questões específicas de um determinado campo de atuação. Esse modo de participação na vida coletiva aproxima-se das dinâmicas próprias dos novos movimentos sociais, que promovem lutas identitárias e reivindicam direitos para as minorias representativas.

Maria Betânia Ávila e Sônia Corrêa (1999) referem-se ao momento instituinte do feminismo, marcado pela transformação dos grupos informais dos anos 1970 e 1980 em ONGs, como uma etapa evolutiva do movimento, com maior potencial de articulação.

\begin{abstract}
Essa nova feição institucional do movimento tem sido problematizada por cientistas sociais e ativistas, segundo os quais a mutação dos grupos/coletivos feministas em ONGs significa perda de autonomia política e deflagra uma nova lógica de poder no interior do movimento. Não obstante, parece-nos, ao contrário, que o processo instituinte e, mais especificamente, a fundação da Rede, consolida num novo patamar a trajetória do movimento. A existência e a sustentabilidade, na sociedade brasileira, de instituições que têm como prioridade a defesa da saúde e dos direitos reprodutivos e sexuais, asseguram a organicidade da ação social e continuidade dessa agenda no âmbito da própria sociedade. Ou seja, de fato, garante a autonomia do movimento, num contexto em que se tornam mais complexos e exigentes os requisitos da presença na esfera pública e, mais especificamente, da relação com os aparatos estatais e as dinâmicas globais. $(1999$, p. 99)
\end{abstract}

Um pouco diferente do feminismo que existiu nas décadas de 1970 e 80 - com grupos de reflexão, associações fortes, manifestações públicas, de caráter mais unificado -, a década de 1990 é marcada por outro tipo de militância, diante do surgimento das ONGs, que trouxeram ao mesmo tempo a profissionalização e a especialização do movimento. Segundo Ávila e Corrêa, ao longo dos últimos 20 anos, o movimento ganhou legitimidade e visibilidade, embora tenha se distanciado de suas proposições revolucionárias e adotado uma estratégia política de reforma (1999, p. 100).

Trata-se de uma nova fase do movimento feminista, que se organiza a partir de lutas segmentadas. Céli Pinto assim observa a gama de organizações e seus diferentes perfis e formas de intervenção:

Algumas são mobilizadoras, outras prestam assessoria especializada, outras ainda são prestadoras de serviços. Atuam tanto junto à sociedade como junto ao Estado, algumas delas com assento em conselhos, outras sendo 
interlocutoras de ministros e parlamentares. Essa é a fase por que passa o feminismo no Brasil, mas a sua trajetória não acaba aqui. Como muitas outras lutas populares e identitárias no Brasil, o feminismo tem uma longa história pela frente. (2003, p. 106)

Assim, partindo dos diferentes modos de intervenção política operados ao longo da trajetória do movimento feminista, torna-se possível perceber, ao mesmo tempo, a permanência de determinadas temáticas e reivindicações, bem como novas formas de enfrentamento postas em cena pelas organizações que constituem o feminismo nas últimas décadas. Nesse sentido, interessa observar a presença e a atuação da mídia alternativa na história recente do movimento como parte significativa das lutas pela cidadania que construíram historicamente o feminismo como um movimento organizado no País.

\section{Mídia alternativa e resistência feminista}

O movimento feminista desde cedo reconheceu o papel da mídia na produção de estereótipos de gênero. Assim, a crítica ao modo como as mulheres eram representadas nos meios de comunicação, em especial na segunda metade do século XX, acompanhou o processo organizativo do movimento.

É nesse sentido que as experiências dos grupos feministas e de mulheres no Brasil, durante a chamada "segunda onda" do feminismo, apontavam cada vez mais para a necessidade de criar um discurso próprio, capaz de fazer questionamentos e promover mudanças. ${ }^{6}$ Exemplo disso foi um Encontro do Movimento das Mulheres no Brasil, realizado no Rio de Janeiro em agosto de 1981, em que entre as temáticas discutidas ganhava destaque a comunicação. O evento, transcrito no livro Mulheres em Movimento, discutiu o papel educativo dos meios de comunicação, considerando que cumprem "não apenas o seu sentido conservador de reprodução da ideologia dominante, mas também, o seu sentido de mudança enquanto focos de resistência e propagadores das novas ideias e valores" (BARSTED, 1983, p. 13).

Ao abordar a importância da criação ou reapropriação da mídia, Leila Barsted observa que na década de 1970 novos espaços foram surgindo para dar voz às mulheres,

\footnotetext{
${ }^{6}$ Entre as diversas experiências de imprensa feminista registradas a partir dos anos 1970, destacam-se os jornais Brasil Mulher (1975-1979), Nós Mulheres (1976-1978) e Mulherio (1981-1987).
} 
a partir de meios variados: revistas, boletins, jornais alternativos, luta por espaço dentro da grande imprensa, do rádio, da televisão e do cinema. Para ela, "os veículos de comunicação se apresentam inseridos numa estratégia de educação do movimento feminista, de recriação da identidade social da mulher e de resgate de nossa história." (1983, p. 16)

No presente artigo, busca-se discutir algumas experiências lançadas pelas organizações feministas no terreno do jornalismo impresso, que compreendem os jornais Fêmea (do Centro Feminista de Estudos e Assessoria - CFEMEA), Fazendo Gênero (do grupo Transas do Corpo), Jornal da Rede (da Rede Feminista de Saúde, Direitos Sexuais e Direitos Reprodutivos) e Folha Feminista (da Sempreviva Organização Feminista), tendo como elementos ilustrativos as edições publicadas nos anos de 2006 e 2007. Assim, discute-se inicialmente a imprensa feminista como uma modalidade da mídia alternativa, para, em seguida, traçar um breve perfil das quatro organizações feministas consideradas e sua respectiva produção midiática. Para observação dos jornais feministas serão considerados os principais aspectos técnicos e editoriais dos produtos, enfatizando a orientação editorial das publicações, as temáticas predominantes e o modo como elaboram os seus discursos. Trata-se, portanto, de uma leitura sobre o viés político e as estratégias midiáticas das organizações feministas consideradas, de modo a reconhecer o jornalismo alternativo como espaço de construção de discursos contra-hegemônicos e de identidades de resistência.

\section{Imprensa feminista nas rotas de comunicação alternativa}

A história do feminismo está entrelaçada com a história da mídia alternativa, uma vez que as mulheres desde cedo perceberam a necessidade de se fazerem ouvir, apostando em um discurso combativo que assumiu, em alguns momentos, o duplo papel de denunciar e de mobilizar as mulheres na defesa dos seus direitos e na conquista da cidadania.

Atualmente, percebe-se que inúmeros grupos que compõem o movimento feminista contam com veículos de comunicação, nos mais diversos formatos e suportes (impresso, sonoro, audiovisual, on-line), que atuam em uma lógica de contrainformação, promovendo o debate e apresentando as reivindicações das mulheres. 
Contudo, investigar a mídia produzida pelas organizações feministas exige uma tentativa de melhor caracterizar o que se entende por comunicação alternativa, uma vez que há abordagens diferenciadas para compreender tal conceito. Embora o termo 'alternativo' remeta, no contexto brasileiro, às publicações que surgiram a partir dos anos 1960, durante a ditadura militar, observa-se a permanência da sua validade, mesmo diante de especificidades que caracterizam as novas formas de comunicação dos grupos e movimentos sociais. Atualmente, a ideia de mídia alternativa não contempla apenas o aspecto de oposição política, mas também outras expressões - por vezes menos 'combativas' - de diferentes grupos sociais que buscam manifestar ideias, projetos e lutas por meio da comunicação. O que se mantém, contudo, é o significado que tais produções assumem na defesa da liberdade de expressão das minorias sociais e do direito de comunicar como parte das lutas pela cidadania (PERUZZO, 2004).

No contexto deste trabalho, compreende-se a mídia alternativa a partir do seu caráter

contra-hegemônico e dos parâmetros diferenciados dos meios tradicionais no que se refere às suas formas de produção, circulação e consumo, assumindo características próprias. Em outros termos, está se considerando como mídia alternativa a produção de grupos e movimentos sociais, que criam canais de resistência e promoção de lutas através dos seus espaços de comunicação, em diferentes suportes.

Para Grinberg, é alternativo todo meio que "implica uma opção frente ao discurso dominante" (1987, p. 18), de tal modo que o alternativo é possível através de diferentes meios e formas de comunicação:

\footnotetext{
Não propomos uma alternativa aos media como tais, mas enquanto instrumentos do poder; e, inversamente, o meio não é em si o alternativo (ou não o é necessariamente), mas o instrumento de uma opção promovida por um grupo de pessoas ou por um setor social. (1987, p. 19-20)
}

Assim, para o autor, o alternativo surge para gerar mensagens com concepções diferentes ou opostas às difundidas pelos meios dominantes, apresentando uma diferença qualitativa em relação aos meios hegemônicos. A ênfase, portanto, está no conteúdo: "sem discurso alternativo não há meio alternativo" (1987, p. 29).

John Downing, em sua abordagem sobre a 'mídia radical', mostra que as mídias efêmeras e de pequeno alcance não são irrelevantes, conforme se constata em inúmeras 
experiências que marcaram a história dos movimentos de resistência. Para o autor, a mídia radical é aquela que expressa "uma visão alternativa às políticas, prioridades e perspectivas hegemônicas", que se apresenta numa enorme variedade de formatos e exerce múltiplos impactos, em diferentes níveis, apresentando-se de forma mais democrática do que a mídia hegemônica.

Percebe-se, a partir destas considerações, que os grupos utilizam a mídia com diferentes propósitos, e acionam determinadas práticas que contribuem com o processo de conquista da cidadania. Assim, para além de uma lógica meramente instrumental, a mídia ocupa um lugar central na resistência às múltiplas formas de opressão. A produção midiática das organizações feministas que compreendem este artigo toma como referência esses aspectos da mídia alternativa, em que se destaca o papel dos meios como instrumentos de articulação das lutas das mulheres.

Considera-se que os veículos se enquadram como alternativos por representarem os interesses de grupos organizados da sociedade civil (ONGs), que se filiam às causas do movimento feminista. O caráter de resistência presente nos veículos alternativos situa-se, portanto, na característica contra-hegemônica que norteia as ações das organizações feministas.

\section{Jornais feministas e estratégias de ação política}

Nas páginas a seguir serão levantadas algumas características das quatro publicações feministas que compreendem o objeto deste trabalho, trazendo algumas informações sobre as organizações, necessárias para situar o seu campo de ação feminista. Nesse sentido, será realizada uma abordagem dos aspectos técnicos e editoriais dos jornais Fêmea, Fazendo Gênero, Jornal da Rede e Folha Feminista, de modo a elucidar o modo como se traduzem em mecanismos de militância feminista. ${ }^{7}$

O Transas do Corpo, um dos mais antigos grupos feministas brasileiros, criado em 1987 e sediado em Goiânia, tem a comunicação como uma das prioridades da organização. Nesse sentido, o grupo desenvolve ações voltadas para a sensibilização dos

\footnotetext{
${ }^{7}$ As organizações feministas contam atualmente com diversos outros espaços de comunicação, nos formatos on-line (sites e boletins), sonoros (programas de rádio), audiovisuais (vídeos e documentários), bem como materiais educativos e institucionais. Porém, nos limites deste artigo, serão mencionadas apenas as produções impressas de caráter jornalístico mantidas pelas quatro entidades mencionadas.
} 
diversos veículos de comunicação para as temáticas de relevância para a mulher e editava, quadrimestralmente, o boletim Fazendo Gênero - um dos focos deste trabalho -, que teve sua publicação interrompida em 2008.

A produção de caráter jornalístico do Transas do Corpo é o jornal Fazendo Gênero, publicação em formato tabloide, de 4 páginas, com impressão em uma cor (rosa). O primeiro número do jornal foi lançado em 1997, quando o grupo comemorava 10 anos de existência. Sua periodicidade, até 2008, foi quadrimestral e as páginas contavam com algumas fotos e imagens em preto e branco.

A edição comemorativa dos 10 anos do jornal (n. 30, 2007/2008), que foi uma espécie de 'despedida', oferece muitos elementos para analisar a comunicação como estratégia organizacional da entidade. No texto a seguir, publicado com o título "10 anos Fazendo Gênero" (editorial, p. 02), é mencionado um levantamento dos principais assuntos tratados no jornal e abordada a importância de uma política de comunicação da organização.

\begin{abstract}
Com base em um levantamento feito nos arquivos do Transas, verifica-se que, ao longo do trajeto da $1 .^{\text {a à }} 30 .^{a}$ edição, as temáticas que mais se repetiram no boletim foram, em primeiro lugar, institucionais, direitos sexuais e reprodutivos, saúde da mulher e feminismo. Em segundo, vêm as matérias sobre métodos contraceptivos, adolescência e juventude, terceiro setor e sexualidade. Mídia, violência contra a mulher, políticas públicas para as mulheres, educação sexual e gênero estão em terceiro lugar no ranking de temáticas abordadas pelo boletim nestes dez anos. (Fazendo Gênero, n. 30, 2007/2008)
\end{abstract}

Neste período de dez anos, o Fazendo Gênero passou por mudanças de formato, de aumento de tiragem, a criação do conselho editorial e a predominância da versão online do jornal (inicialmente, era distribuído pelo correio para todo o Brasil). O jornal ${ }^{8}$ apresenta as seguintes editorias fixas: "saúde" (texto informativo localizado na página 3); "o que rola" (coluna na página 4, com divulgação de eventos e atividades do Transas e outras entidades), "o que rolou" (coluna sobre eventos e atividades que ocorreram no período) e "resenha" (coluna na página 4 com resenha de livro). Em duas das edições observadas foram utilizados textos de entrevistas.

O público-alvo do jornal são grupos feministas, mas não se pode afirmar o

\footnotetext{
${ }^{8} \mathrm{O}$ corpus de pesquisa compreende as seguintes edições do jornal Fazendo Gênero: ano X, n. 28, março a junho de 2007; ano X, n. 29, julho a outubro de 2007; ano X, n. 30, novembro de 2007 a fevereiro de 2008.
} 
alcance dessa ação de mídia, pois o jornal não informa sua tiragem e as edições são também disponibilizadas em formato on-line. No Fazendo Gênero, predomina a estrutura informativa, mas também é possível encontrar textos de caráter institucional (como na edição de 20 anos do grupo). A perspectiva de gênero e a identificação com o feminismo são as principais marcas identitárias do jornal, através das quais são abordados temas ligados, principalmente, à sexualidade e ao direito ao corpo, além de textos sobre comunicação e eventos feministas.

O jornal Fazendo Gênero aborda a questão do aborto em uma de suas edições (n. 29, 2007), em que traz informações, entrevista e artigos sobre o tema, apresentando o comprometimento do movimento feminista com o direito das mulheres de decidirem sobre seus corpos. O jornal publica dados sobre aborto e mortalidade materna e iniciativas no campo das políticas públicas em seus textos opinativos, de modo a fortalecer um discurso em defesa do aborto no Brasil. Os fragmentos de texto a seguir, de autoria de Roberto Arraida Lorea ("Em defesa das liberdades laicas") e Albineiar Plaza Pinto ("Complicações do aborto clandestino no Brasil”), respectivamente, ilustram a orientação editorial do jornal:

O debate sobre o aborto não produz consenso. Como resultado, nas sociedades democráticas, as mulheres não são obrigadas a abortar, pois gozam de autonomia reprodutiva. Pelo mesmo fundamento, não são obrigadas a levar a termo a gravidez indesejada. (Fazendo Gênero, 2007, p. 02)

Há décadas o movimento de mulheres vem denunciando as condições inseguras da realização de abortos clandestinos, que colocam em risco a vida de tantas mulheres - especialmente as pobres, negras e jovens. Revisitar o tema é necessidade e lamento.

(...) Para a mulher, o contexto de uma gravidez indesejada é quase sempre de crise e risco. A garantia de que ela receba atenção integral, apropriada, e oportuna nas situações de abortamento é um direito constitucional ainda não concretizado, assim como o direito de acesso à informação (escola com educação sexual e conhecimento dos métodos contraceptivos) e aos métodos contraceptivos, como a pílula do dia seguinte. (Fazendo Gênero, 2007, p. 03)

Outra organização feminista, o Centro Feminista de Estudos e Assessoria CFEMEA, é uma entidade não governamental, sem fins lucrativos, fundada em julho de 1989 em Brasília/DF, que trabalha "pela cidadania das mulheres e pela igualdade de gênero". A organização participa do "movimento nacional de mulheres", integra articulações e redes feministas internacionais, especialmente da América Latina, além de participar de diferentes iniciativas para o combate ao racismo. 
O jornal Fêmea ${ }^{9}$, principal publicação do CFEMEA, é um periódico criado em 1992, que se constitui como um importante canal de comunicação entre o movimento feminista e os atores políticos. De acordo com a organização, o informativo "aborda as questões referentes aos direitos das mulheres no Congresso Nacional e os grandes temas da agenda nacional do movimento de mulheres". Desde 1999 disponível no site do CFEMEA, dirige-se a organizações de mulheres de diferentes áreas de atuação e a parlamentares e assessores(as) legislativos(as).

O Fêmea possui uma tiragem de 13.000 exemplares (além dos acessos on-line), abrangência nacional e a periodicidade, que já foi trimestral, é atualmente mensal (desde 2008). As edições são em formato tabloide, com 12 páginas. Até o ano de 2007, a impressão era feita em apenas uma cor (rosa), e o jornal contava com poucos recursos de imagem; porém, a partir de 2008, passou por uma reformulação, sendo atualmente impresso em cores, com fotos e uma boa apresentação visual.

Na edição de junho/agosto de 2008 (ano X, n. 156), quando o jornal passa por um processo de reformulação, publica em seu editorial um texto que esclarece sobre os objetivos da publicação:

Temos a satisfação de fazer chegar a suas mãos a edição 156 do Fêmea. Desde o primeiro número, nosso jornal busca ser um instrumento para fazer avançar a luta das mulheres pela igualdade de direitos, na lei e na vida.

Modéstia à parte, o Fêmea se consolidou como uma referência, um veículo que subsidia a discussão e provoca a ação das mulheres nos movimentos sociais, nas Câmaras de Vereadores, Assembleias Legislativas e no Congresso Nacional; nos conselhos e nos organismos governamentais de promoção da igualdade. Travamos duras e intermináveis lutas para garantir às mulheres o direito de interromper uma gravidez indesejada e de decidir sobre o seu próprio corpo; e também participamos das batalhas vitoriosas que permitiram às mulheres avançar em termos de prevenção, punição e proteção contra a violência doméstica e sexual. (jun./ago. 2008)

Um aspecto que caracteriza a proposta editorial do Fêmea é a análise e avaliação dos temas em debate no cenário político, com base em um viés feminista. Essa questão é mencionada no editorial de uma de suas edições: "Outro aspecto que nos desafia a

\footnotetext{
${ }^{9}$ O material selecionado contempla três edições do ano-base (2007): jan./jul. 2007; set./out. 2007; nov./dez. 2007, e outras duas edições que se mostraram relevantes para a pesquisa: jun./2005 (15 anos do CFEMEA, com textos sobre o tema do aborto); e jun/ago. 2008, quando o jornal apresenta um novo formato.
} 
cada edição é, em cima da hora, analisar, avaliar e interpretar, numa perspectiva feminista, os fatos que revelam as disputas das mulheres por seus direitos, por igualdade, liberdade e justiça" (Fêmea, jun./ago. 2008).

Tendo como marco do seu discurso as questões de gênero e direitos das mulheres, o jornal traz assuntos ligados aos direitos reprodutivos, apresentando o aborto e as políticas públicas como temas predominantes nas edições observadas. E, no que diz respeito à linguagem, as páginas do Fêmea são ricas em informações, debates e análises, que evidenciam o comprometimento com as causas feministas.

Em uma edição sobre aborto (jun. 2005; n. 145), o Fêmea publicou textos escritos por participantes das Jornadas Brasileiras pelo Direito ao Aborto Legal e Seguro, levantando várias questões a respeito do debate atual sobre o assunto, a partir da atuação das entidades, e trazendo ainda um encarte com as proposições relacionadas ao aborto no Congresso Nacional. Observa-se, assim, que em sintonia com o trabalho de advocacy realizado pela organização, destaca-se nas páginas do jornal a reivindicação do direito ao aborto, conforme se pode observar no texto a seguir, sob o título "Direitos sexuais e reprodutivos em risco", que esclarece sobre os projetos de lei referentes à questão:

As últimas semanas de atividades do Congresso Nacional marcaram a entrada em pauta de três propostas legislativas relacionadas ao abortamento - os projetos de lei (PL) 1135/1991 e 1763/2007, e o projeto de decreto legislativo 1494/2004. O primeiro permite a prática, sem restrições, até a 12. ${ }^{a}$ semana de gestação. O segundo concede um salário mínimo mensal à mulher que levar adiante uma gestação resultante de estupro até que a criança complete 18 anos. E por fim a proposta originada no Senado convoca plebiscito a respeito de temas polêmicos, entre os quais o aborto.

Os pareceres às duas primeiras propostas anunciadas na Câmara dos Deputados revelam como o legislativo tem enfrentado o tema dos direitos sexuais e reprodutivos das mulheres. A opção não foi apenas de não avançar na legislação que se refere ao tema, mas também de retirar direitos já garantidos às mulheres.

[...] Já o PL 1763/2007, de autoria da deputada Jusmari Oliveira (PR-BA) e do deputado Henrique Afonso (PT-AC), prevê pagamento de um salário mínimo para mulheres não interromperem a gravidez causada por um estupro. O benefício seria concedido até que a criança completasse 18 anos, mas apenas depois que a sentença transitasse em julgado, ou seja, quando não couber mais qualquer recurso no processo. Para se ter ideia, o julgamento dos crimes de estupro leva, em média, três anos. Outro impeditivo é que, se o acusado não for encontrado, o processo é arquivado. Essas exigências tornam a medida inócua, além de partirem do pressuposto que as mulheres mentirão para receber o benefício. Com parecer favorável do deputado José Linhares (PP-CE), o PL está pronto para ser apreciado no plenário da CSSF. (Fêmea, nov./dez. 2007, p. 10-11) 
O texto, além de discutir o conteúdo dos projetos e esclarecer sobre suas implicações, traz também o posicionamento do movimento feminista sobre o assunto, de modo a demarcar a visão do movimento sobre o direito ao aborto. Assim, o engajamento com a causa revela-se através de um discurso de resistência projetado pelo jornal. Sobre o PL 1763/2007, o CFEMEA inseriu o debate na agenda pública ao batizálo, ironicamente, de "bolsa estupro". O jornal assim expressa sua avaliação sobre a proposta:

\begin{abstract}
Apesar de seu verniz condescende e assistencialista em relação às mulheres, o objetivo do PL é evitar a prática do aborto legal com a oferta de dinheiro. É uma desautorização do Código Penal, que ainda em 1940, legalizou o aborto nessas condições e um retrocesso ao que a sociedade já compreende como direito das mulheres. A iniciativa também banaliza o impacto do estupro para a vítima, já que, por R\$ 380,00, Henrique Afonso, Jusmari Oliveira e o relator, Padre José Linhares (PP-CE), esperam que a vítima supere o que lhe aconteceu e assuma o filho sozinha. (Fêmea, nov./dez. 2007, p. 10-11)
\end{abstract}

Outro texto publicado no jornal Fêmea denuncia a falta de comprometimento do Estado com a revisão da legislação sobre o aborto. Sob o título "Democracia é garantir direitos de todas e todos”, o jornal assim aborda a relação entre aborto e cidadania:

Todos os anos, cerca de um milhão de brasileiras são alijadas de sua cidadania. Ao se depararem com uma gravidez indesejada, acabam por recorrer a métodos inseguros para interromper essa gestação. O Estado, que deveria garantir a elas o direito à saúde, prefere não rever de forma séria a legislação sobre o aborto. Ao não tornar a legislação mais inclusiva, esse mesmo Estado impõe assim a todos os cidadãos e cidadãs interesses de alguns setores da sociedade.

O resultado disso é que centenas de mulheres morrem todos os anos por complicações de abortamentos inseguros e ilegais e outras milhares passam a conviver com sequelas graves. O dia 28 de setembro - Dia de Luta pela Descriminalização e Legalização do Aborto na América Latina e no Caribe é uma data de mobilização e reflexão para que o Brasil avance nessa questão e inclua definitivamente os direitos sexuais e reprodutivos em sua agenda democrática. (Fêmea, set./out. 2007, p. 4-5)

No mesmo texto, discute-se a dimensão política da legislação sobre o aborto, de modo a elucidar as interferências de setores religiosos nas decisões que envolvem os direitos reprodutivos, em especial no que se refere ao aborto. O que a ONG faz, por meio do jornal, é mobilizar discursos sobre leis e direitos, compondo argumentos de defesa da autonomia das mulheres. O Fêmea traz o seguinte panorama sobre as posições antiaborto: ${ }^{10}$

\footnotetext{
${ }^{10} \mathrm{O}$ jornal apresenta um quadro com projetos apresentados em 2007, mostrando que a atual legislatura é
} 


\begin{abstract}
Uma das barreiras a serem ultrapassadas é a configuração atual do Congresso Nacional. Dos 513 deputados federais, 166 fazem parte da Frente Parlamentar contra a Legalização do Aborto - Pelo Direito à Vida, o que representa 32\%. No Senado Federal, 28 ocupantes das 81 cadeiras são signatári@s do grupo - 34\%. Há ainda a Frente Parlamentar Mista em Defesa da Vida - Contra o Aborto, e as Frentes Evangélicas e em Defesa da Vida, cujos integrantes também já se manifestaram contra a legalização. (...) Levantamento realizado pelo CFEMEA mostra que das cinco propostas legislativas apresentadas na Câmara dos Deputados até julho de 2007, três negam às vítimas de estupro o direito ao aborto seguro. Além disso, um deles tenta transformar a prática em crime hediondo. O que se vê, na verdade, é um recrudescimento da criminalização da mulher e um retrocesso nos direitos já conquistados. (Fêmea, set./out. 2007, p. 4-5)
\end{abstract}

Em sintonia com o debate feminista, a Rede Feminista de Saúde é uma articulação do movimento de mulheres que soma "266 entidades - entre grupos de mulheres, ONGs, núcleos de pesquisa, organizações sindicais/profissionais e conselhos de direitos da mulher - além de profissionais de saúde e ativistas feministas". ${ }^{11}$ A Rede foi criada em agosto de 1991, em Porto Alegre, reunindo 40 organizações feministas do País que atuavam no campo dos direitos sexuais e reprodutivos.

No formato jornalístico impresso, a Rede publicou até 2006 o Jornal da Rede Feminista de Saúde, uma publicação em formato de revista (tamanho A-4 e impressão em papel couchet), com 36 páginas e impressão em uma cor, com capa colorida (com foto ou arte), contendo textos em forma de artigos opinativos e análises. Com periodicidade indefinida, foram publicadas em média três edições por ano, de 1999 a 2002, e apenas uma nos anos de 2004 a $2006 .^{12}$

Nas edições do Jornal da Rede ${ }^{13}$, o tema da mortalidade materna é predominante, mas também se observa a presença de temas como políticas de saúde,

uma das mais conservadoras dos últimos tempos no que se refere aos direitos sexuais e reprodutivos, alertando para o perigo de retrocesso nos direitos conquistados pelas mulheres. Entre as propostas mencionadas pelo CFEMEA sobre o assunto está a criação de código de acesso telefônico para recebimento de denúncias de abortos clandestinos, a instituição do Dia do Nascituro ou Dia Nacional da Defesa da Vida, a proibição da distribuição e comercialização de método de anticoncepção de emergência, além de projetos que dispõem sobre o Estatuto do Nascituro, considerando o momento da concepção o início da vida.

11 Informações divulgadas no site da Rede: <http://www.redesaude.org.br>. Acesso em: setembro de 2007.

${ }^{12}$ Esta observação toma como base as edições publicadas no site da Rede. A primeira edição disponível é de n. 17, datada de maio de 1999, e a última é de n. 28, de julho de 2006.

13 Foram adquiridas em versão impressa duas edições da publicação: n. 27, setembro de 2005 ("PAISM, 20 anos depois") e n. 28, julho de 2006 (“A morte materna possui responsáveis”), que compõem o corpus da pesquisa. Outras edições da revista foram consultadas em formato digital, através do site da entidade. 
racismo, violência, trabalho e direitos sexuais nas páginas da revista. O público da revista é formado por grupos feministas de todo país e a estrutura discursiva predominante é a opinativa (com explicitação de um discurso político), conjugada com a informativa (com informações e análises). Os textos apresentam dados, análises e argumentos sobre os temas da revista, destacando as lutas das mulheres no campo da saúde pública.

O Jornal da Rede conta com os seguintes espaços: Seções, com artigos sobre a temática da publicação, em uma média de cinco textos; e Editorias, que se divide em Direito, Saúde Pública, Perfil (entrevistas com pessoas ligadas à luta das mulheres pelos direitos sexuais e reprodutivos) e Em pauta (com publicações e lançamentos).

A Sempreviva Organização Feminista (SOF), organização não governamental feminista criada em 1963, com sede em São Paulo e atuação em nível nacional, também conta com veículos de comunicação em suas estratégias de luta. ${ }^{14}$ Tendo como público prioritário as mulheres organizadas no movimento autônomo de mulheres, movimento popular e sindical, rural e urbano, a SOF dedica-se a promover o debate feminista, em especial sobre o tema da economia feminista. ${ }^{15}$ Segundo informações disponíveis no site da SOF, suas linhas de atuação são formação feminista, assessoria e acompanhamento de políticas públicas, publicação e difusão, construção e articulação, e desenvolvimento organizacional.

A SOF publica a Folha Feminista, jornal que, em sintonia com o projeto político da organização, propõe debates envolvendo o feminismo, o machismo e o mercado. ${ }^{16} \mathrm{~A}$ Folha Feminista, embora se pretenda mensal, não tem uma periodicidade regular e possui uma tiragem de 1.500 exemplares (com 4 páginas em tamanho A-4), que circulam entre grupos feministas, além da versão on-line, disponível no site da $\mathrm{ONG}^{17}$

\footnotetext{
${ }^{14}$ A SOF produziu vídeos nos anos 1990 (sobre aborto e laqueadura) e publica a coleção "Cadernos Sempreviva", que são livros que abordam temas relativos aos direitos das mulheres, além do jornal Folha Feminista.

${ }^{15}$ A SOF assim descreve seus objetivos: "contribuir na construção de uma política feminista articulada ao projeto democrático-popular, que esteja presente na formulação de propostas e nos processos organizativos e de luta dos movimentos sociais. Esta política deve transformar as relações de gênero e favorecer a autodeterminação das mulheres". Disponível em: <http://www.sof.org.br/>. Acesso em: $28 / 11 / 2009$.

${ }^{16}$ No editorial de dezembro de 2008 (n. 67), a Folha Feminista anuncia: "Em 2009, seguiremos em luta para alterar o paradigma dominante e ampliar a construção de alternativas baseadas na sustentabilidade da vida humana".

${ }^{17}$ A Folha Feminista, em novembro de 2009, chegou à edição de número 69.
} 
Nas edições da Folha Feminista ${ }^{18}$, verificam-se os seguintes espaços: editorial (página 1), artigo (páginas 1 e 2), texto sobre ações do movimento feminista (página 3), resenha e agenda do movimento feminista (página 4). Os temas predominantes nas edições observadas são diversidade sexual (na perspectiva lésbica), economia solidária, machismo e crítica à imagem das mulheres nos meios de comunicação. $\mathrm{O}$ discurso do jornal é opinativo, com forte viés político, o que evidencia o caráter de militância feminista a que o veículo se propõe.

A observação das produções impressas das organizações feministas evidencia o processo de construção de identidades de resistência e a luta pelos direitos das mulheres no campo da sexualidade e da reprodução, a partir da elaboração de conteúdos críticos que projetam o feminismo como prática política. Porém, revela ainda que há uma carência de espaços informativos capazes de estabelecer a articulação no interior do movimento.

Além disso, a ausência de profissionais da comunicação e as dificuldades financeiras vivenciadas pelas organizações muitas vezes impedem que a comunicação seja vista como um lugar estratégico em que se configuram as lutas pelos direitos das mulheres. E, sem uma proposta editorial clara e uma linguagem voltada ao público a que se destinam, as produções de mídia correm o risco de não ecoarem nos espaços pretendidos, ou parecerem desconectadas do seu universo de ação.

\section{Considerações finais}

Nos limites deste texto, buscou-se apresentar alguns elementos que caracterizam a produção jornalística de quatro organizações feministas, projetando assim algumas especificidades e aproximações no uso da mídia como mecanismo de ação política. Porém, para além de constatar a existência de veículos de caráter contra-hegemônico, é preciso também problematizar essa produção, indicando alguns limites e, do mesmo modo, potencialidades como espaço de debate e articulação feminista.

Algumas limitações situam-se no alcance, na falta de regularidade e mesmo no uso de uma linguagem nem sempre adaptada ao público a que se destina, conforme se

\footnotetext{
${ }^{18}$ Foram observadas as edições de junho e setembro de 2007 (n. 64 e n. 65, respectivamente) e outras edições variadas do jornal para traçar algumas características do veículo.
} 
pode observar em alguns jornais. O jornal Fêmea, por trabalhar com informação especializada e apresentar análises sobre temas em discussão no Legislativo, já se consolidou como uma referência no processo de mediação entre as demandas do movimento feminista e os responsáveis pela formulação de leis. E, por manter uma regularidade em suas ações, também atua como fonte para a mídia, o que contribui para a visibilidade do debate feminista para um público mais amplo.

Já o Fazendo Gênero, voltado aos grupos feministas, apresenta como proposta editorial a articulação com o movimento, ao trabalhar temas de interesse das organizações e divulgar a agenda de atividades. Porém, a periodicidade quadrimestral impede uma presença mais efetiva junto às organizações e a ausência de dados sobre a produção e a forma de circulação do material compromete uma avaliação mais profunda sobre o alcance e a repercussão do jornal, que deixou de circular em 2008.

O jornal da Rede Feminista de Saúde, Direitos Sexuais e Reprodutivos, por sua vez, tem na falta de regularidade dos produtos um fator que limita o alcance dos discursos. O Jornal da Rede, que em alguns anos contou com três e em outros com apenas uma edição e deixou de circular em 2006, apresentava diversos textos sobre temas ligados à saúde da mulher. Acredita-se que o público preferencial dessa publicação era formado por organizações feministas e de mulheres; porém, também parece estar presente o interesse de profissionais da área da saúde e organismos responsáveis pela formulação de políticas públicas, devido ao conteúdo formado por dados, análises e opiniões sobre temas dos direitos das mulheres no campo dos direitos sexuais e reprodutivos. ${ }^{19}$

A Folha Feminista, entretanto, tem como público as próprias organizações feministas, e por isso a linguagem é voltada para a defesa das bandeiras do movimento. Mas a periodicidade irregular também acaba comprometendo seu efetivo papel na tematização regular de certas demandas das mulheres (ainda que as ações de comunicação da ONG não se reduzam ao periódico).

É importante considerar ainda que o enfraquecimento de algumas produções de mídia impressa, atualmente, a exemplo das experiências mencionadas, representa não necessariamente a falta de estratégias de mídia, mas um processo de migração para

\footnotetext{
${ }^{19}$ A Rede Feminista mantém atualmente um boletim on-line que cumpre o papel informativo e divulga regularmente as ações do movimento. Essa produção, que circulou em formato impresso até 2009, não foi mencionada neste artigo por não configurar nos propósitos do trabalho.
} 
outros formatos de comunicação. Percebe-se que, cada vez mais, o movimento utiliza sites, boletins on-line e mesmo conteúdos em formatos de áudio e vídeo nos sites e portais, além da relevante presença das organizações nas redes sociais. Trata-se, portanto, de um momento de transição das práticas de militância, que incorporam em suas lutas a visibilidade na mídia, em diversos formatos e suportes.

No texto "Publicar é uma ação política", Jacira Melo (2003) observa que, para que as publicações feministas constituam uma ação política direta, e não apenas um instrumento de divulgação das organizações, é preciso investir mais na preparação dos textos, para que se adaptem às necessidades e interesses do público, na profissionalização do processo editorial, no planejamento da distribuição dos materiais, na avaliação da recepção dos produtos, entre outros aspectos.

Portanto, diante da contribuição dos jornais considerados para o debate feminista, em diferentes perspectivas, pode-se dizer que o jornalismo, no contexto das organizações, constitui uma forma de ativismo que integra as lutas pela cidadania feminina. É nesse sentido que se torna importante refletir sobre as produções midiáticas que marcaram a trajetória do movimento e projetar a necessidade de pensar a mídia alternativa como um espaço de mobilização, visibilidade e fortalecimento das demandas feministas.

\section{REFERÊNCIAS}

ÁVILA, Maria Betânia; CORRÊA, Sonia. O movimento de saúde e direitos reprodutivos no Brasil: revisitando percursos. In: GALVÃO, Loren; DÍAZ, Juan (Orgs.). Saúde sexual e reprodutiva no Brasil: dilemas e desafios. São Paulo: Hucitec; Population Council, 1999. p. 70-103.

BARSTED, Leila Linhares. Comunicação: é falando que a gente se entende. In: PROJETO MULHER. Mulheres em Movimento. Rio de Janeiro: Editora Marco Zero; Instituto de Ação Cultural,1983. p. 13-16.

CARDOSO, Elizabeth. "Imprensa brasileira pós-1974”. Estudos Feministas. Florianópolis: CFH/CCE/UFSC. v. 12, n. especial, 2004. p. 37-55.

COGO, Denise. Mídia, identidades culturais e cidadania: sobre cenários e políticas de visibilidade midiática dos movimentos sociais. In: PERUZZO, Cicília M. Krohling (Org.). Vozes cidadãs: aspectos teóricos e análises de experiências de comunicação popular e sindical na América Latina. São Paulo: Angellara Editora, 2004. p. 41-56.

DOWNING, J. Mídia radical: rebeldia nas comunicações e movimentos sociais. São Paulo: Senac, 2002.

FESTA, Regina. Comunicação popular e alternativa no Brasil. São Paulo: Paulinas, 
1986.

GRINBERG, Máximo Simpson. Comunicação alternativa: dimensões, limites, possibilidades. In: GRINBERG, Máximo Simpson (Org.). A comunicação alternativa na América Latina. Petrópolis: Vozes, 1987.

MELO, Jacira. Publicar é uma ação política. Revista Estudos Feministas. Florianópolis: CFH/CCE/UFSC, v. 11. n. 1, 2003. p. 298-301.

MIGUEL, Sônia Malheiros. "Publicando nas ONGs feministas: entre a academia e a militância". Revista Estudos Feministas. Florianópolis: CFH/CCE/UFSC, v. 11. n. 1, 2003. p. 271-283.

PERUZZO, Cicília M. Krohling. Comunicação nos movimentos populares - a participação na construção da cidadania. 3. ed. Petrópolis: Vozes, 2004.

PINTO, Céli Regina Jardim. Uma história do feminismo no Brasil. São Paulo: F. Perseu Abramo, 2003.

Movimentos sociais: espaços privilegiados da mulher enquanto sujeito político. In: COSTA, Albertina de Oliveira; BRUSCHINI, Cristina. (Orgs). Uma Questão de Gênero. Rio de Janeiro: Rosa dos Tempos; São Paulo: Fundação Carlos Chagas, 1992. p. $127-150$.

TONELI, Maria Juracy Filgueiras. Publicações feministas sediadas em ONGs: limites, alcances e possibilidades. Revista Estudos Feministas. v. 11, n. 1, 2003. p. 265-270. 